\title{
Students satisfaction with the online teaching process
}

Denis Areșan, BSc.

West University of Timisoara, Romania

Assoc. Prof. Laurențiu Gabriel Țîru, PhD

West University of Timisoara, Romania

\section{Abstract}

This study is about student satisfaction in the online teaching process. The pandemic situation forced us to move the educational activities in the online environment for the safety of all its participants.

The methodological design is the quantitative one, the research method used is the sociological survey. This study tried to identify students' perception, effectiveness, satisfaction, and self-perceived efficiency regarding the teaching process in the online environment.

The questionnaire was translated and adapted into Romanian. It consists of 26 questions, divided into five dimensions. The sampling method was the non-probabilistic convenience one, with voluntary participation.

The results provided tell us those female respondents were more open to online methods, resulting in higher satisfaction despite common knowledge. However, the results should be viewed with reservations, as the data collected are not homogeneous, and the respondents were chosen by the voluntary participation method. This approach can be seen as a starting point for future research related to the satisfaction of the teaching process through e-learning.

Keywords: e-learning; satisfaction; online teaching; online virtual learning.

\section{Introduction}

The current pandemic situation forces us to move the teaching activity online for the safety of everyone who engages in this process. The online environment provides access to course materials and interaction between students and teachers.

This learning environment allows us to use multimedia technologies such as text, images, audio files, video files, or animations. Online learning assumes that the teaching process will be carried out in a virtual classroom, the teaching materials will be available on the Internet. A teacher must guide the virtual class. He plans the group's activity, and he submits the materials to debate by asynchronous (Google Classroom) and synchronous methods (chat, Google Meet). 
Online learning means digital learning. To participate actively in this process, students must have the basics of ICT (Information and Computer Technology). ICT includes communication technologies, WI-FI, mobile phones. Electronic learning allows both teachers and students to access materials uploaded to online/e-learning platforms, materials provided by teachers to students, and materials uploaded by students for grading. Recently, a study aimed at using ICT (Gupta \& Gupta, 2020), especially in digital learning, highlights the idea of collaboration and active learning. Harasim (2002) argues that when technology is applied in open and distance learning, the most important aspect of ICT is the potential for collaboration and communication. The study mentions that due to technological development, a new paradigm shift occurs. Teachers need to develop new teaching and learning methods to implement them with students effectively. Online learning should be seen as an opportunity to develop the skills to work online (Azlan et al., 2020).

Online learning is seen differently by each person, this being due to their own experience. The following types of e-learning (Ilie, 2007), characteristics, and technologies that need to be implemented will be presented and described: individual study, facilitated e-learning, instructor-led e-learning.

The individual study model is trying to produce experimental-based support for those who try to be self-learners. The materials provided for this study are stored on a web server and accessed through a browser. Those who follow this model are independent in the learning process. They follow steps to assimilate knowledge because they do not have a teacher to coordinate their activities.

The facilitated e-learning collaboration is based on the web resources offered by a teacher. The teacher's role is to answer questions and solve problems. The teacher acts as an evaluator of the student.

The "virtual class" model uses web technologies to support online classes at a time. A variation of technologies is used: video and audio, chat, application sharing, virtual table.

The teacher presents the subject with the help of PowerPoint slides. Students can ask questions and receive answers through the chat window. The disadvantage of this method is the network's bandwidth, which can affect the quality of information.

\section{Advantages and disadvantages of e-learning}

Learning online requires using a device to communicate. The studies show that students tend to be more active online than in the traditional educational setting (Hung, Chou, \& Chao-Hsiu Chen, 2010). Thus, students have more time to think about a topic of discussion. They overcome the fear of answering questions on the spot. The questions 
engage the students in this process, making it easier for understanding. In addition, to prevent burnout and loss of interest, students should take advantage of the opportunity to work with other students to elaborate on homework. Haavind (2000) argues that e-learning allows students to interact with the teacher and other students and work with their colleagues to complete their educational tasks. The nature of the asynchronous functions within an online course, such as email and e-learning, allows students to think and shy students to engage in conversation (Barbour \& Reeves, 2009).

Palloff \& Pratt (1999) turned their attention to forming a community in cyberspace. They examined relationships between individuals within online communities. They noted that the help from communication technologies changed society from a locationbased community to a cyber one, where individuals and people created a new and different identity from those they had in real life. Since information processing takes longer than face-to-face interaction, we can say that this environment fits more naturally with introverted people. Individuals find it much easier to interact through this created avatar in cyberspace.

Increased availability and evolution of technology have made it easier for computers and mobile phones to access educational institutions, at home or work. Nowadays, most students have internet access both on their computers and on their phones. Connected with this advantage is that students no longer spend time on transport and on the way to university. (Mpofu, 2016)

One advantage offered by e-learning is the flexibility to access courses from any location. E-learning gives both universities and students the flexibility of time and place. E-learning improves the effectiveness of knowledge by accessing a large amount of information (Arkorful \& Abaidoo, 2015).

Another advantage by which the effectiveness of e-learning is improved is it provides the opportunity for students to communicate through e-learning platforms. So, e-learning helps remove barriers that have the potential to prevent participation, including the fear of talking to other students (Arkorful \& Abaidoo, 2015). E-learning can motivate students to interact with others and respect their views, which are not always the same. E-learning facilitates communication, as well as relationships to sustain learning.

Some studies mention that the advantage of e-learning is that the teacher can focus his attention on the students' individual needs. For example, in their book Rosenberg \& Foshay (2002) noted that one crucial advantage of e-learning is focusing on students' needs rather than on the needs of teachers or institutions.

Another advantage is that it allows students to understand the lesson at their own pace, reviewing the material as often as they want. For teamwork, students can 
collaborate through Google Meet. For work tasks and tests, the teacher may limit the time and date for the activity.

Although it offers many advantages, e-learning has disadvantages. For example, despite claims that e-learning can improve the quality of education, it is argued that producing materials online and making them available to students increase learning only for certain specific topics (Mayes, Dineen, McKendree \& Lee, 2002).

It is intended to see whether the transition to a flexible model using technological means, but continuing with the face-to-face model, will be beneficial for students. Students get online courses through different platforms. They could see presentations slides and listen to the teacher's recording. Students who used online platforms during the semester had three hours of face-to-face educational activity. That could look like a hybrid educational system. By combining classic teaching with online, the students' results were improved. The study was done on the same students, who in the previous year attended the classical courses and the following year in the hybrid version (Downling, Godfrey, \& Gyles, 2003).

Mayers et al. (2002) mention that online learning has a complete lack of personal interaction, not just between the teacher and students but between students. He notes that the e-learning system, in which community members do not communicate actively, will make students much shyer in expressing themselves freely and exposing their point of view to the class.

Online learning lacks interaction or networking, which affects the effectiveness of learning objectives. Therefore, students need to acquire a strong motivation and time management ability to reduce those effects.

The educational process is much easier when carried out by the traditional method, face to face, with the teacher. Online education is prone to plagiarism, deception, and lack of learning motivation.

Not all subjects can use online learning as a method in education. For example, some scientific fields that require practical experience are much more difficult to study through online interactions. The researchers argued that e-learning is more appropriate for social and human sciences than in medical science and engineering, where the development of practical skills is needed.

Another disadvantage that does not depend on the student or teacher is the poor connection of the internet that can disrupt the course sessions, leading to poor quality of information and interactions. This problem is more evident for students from rural areas with poor or non-existent internet infrastructure or who cannot afford to pay for it. 
The obvious disadvantage of online teaching is no active interaction between the teacher and the student. The student does not receive immediate clarification when encountering a problem or when a concept is unknown. In addition, due to minimal interaction, students may be less motivated to study on their own.

\section{Methodology}

The methodological design is a quantitative design. The research method is a sociological survey, and the instrument used was the questionnaire. Quantitative design deals with the quantitative measurement and "calculation" of information obtained by applying an empirical approach, which measures the object of study with sufficient precision to present detailed conclusions (Obrad, 2018). The sociological survey is a collection of information on the opinions, attitudes of individuals, results on the behaviors of human groups, their tastes, needs, their motivations for their way of working, living, having fun (Grawitz \& Pinto, 1972). The questionnaire is a sociological research tool through which individuals' opinions and attitudes on a particular topic of social interest can be analyzed. I chose the quantitative design compared to the qualitative design because I wish to have a descriptive image, an overview of this phenomenon. (Chelcea, 1975).

Our research objectives were to identify students' perception of the usefulness of the materials offered in the teaching process; determination of effectiveness in online time interactions; surprise students' satisfaction with online interactions; students' perceived self-efficacy with the use of e-learning platforms; to determine student's ability to use multimedia aspects (camera, microphone, presentations, images, videos) in online learning.

\section{Research instrument}

The questionnaire was written in an online format using the Google Forms platform (https://www.google.com/forms/about/), through which it was more easily distributed for completion. This research tool consists of 26 items about online learning, divided into five dimensions. The questionnaire was adapted from a study of the Moodle platform (Chou, 2014).

The sampling method used, and the selection processes applied.

Non-probabilistic convenience sampling technique was used for this study. The convenience sample was based on voluntary participation. This model implies the inclusion in the sample of available and accessible cases (Murairwa, 2015). As an example, we can take students in a class. They are not a representative sample for all students. In the first phase, we have chosen several subjects that meet the conditions for inclusion in the sample. In the second phase, they were asked to find other respondents who met specific criteria (age, educational level). 


\section{Results}

To highlight the differences between gender and perceived usefulness, we used the T-test for independent samples. The value of the independent T-test was $t(224)=4.77$, $p<0.01$, at a significance threshold of $p=0.033$. Thus, there are significant differences in the perception of male students $(m=3.05, S d=1.82)$ and perceptions of female students $(\mathrm{m}=4.38, \mathrm{Sd}=1.59)$ in terms of the usefulness of online education. Female respondents perceive these methods as more effective and valuable than male respondents, who also consider them effective but to a lesser extent.

The differences between gender and online learning satisfaction were tested with the T-test for independent samples. The result of the Levene $F$ test shows that the groups were homogeneous, the value of Levene $F=2.71$, at a significance threshold $p>0.05$. There are significant differences between the means, highlighted by the value of the independent $t$-test, $t(224)=3.02, p=0.003<0.05$. Thus, there are significant differences between the perception of male students $(m=3.19, \mathrm{Sd}=1.27)$ and the perception of female students $(\mathrm{m}=3.96, \mathrm{Sd}=1.55)$ in terms of satisfaction of using online learning platforms. A possible explanation could be that they adapted to online learning methods more quickly, so they had greater openness to online processes and interactions.

To see the differences between gender and respondents' confidence when using online learning platforms and their functions, we used an independent $\mathrm{t}$-test. The Levene $\mathrm{F}$ test results show that the groups are homogeneous, the value of Levene $F=0.77$, at a significance threshold $p>0.05$. Thus, there are significant differences between the groups' average, highlighted by the value of the independent T-test, $t(224)=3.68, p$ $=0.01<0.05$. There are significant differences between the perception of male students $(m=3.63, S d=1.80)$ and the perception of female students $(m=4.73, S d=1.76)$ in terms of self-satisfaction with the use of online platforms. Female respondents have a higher degree of confidence in using online platforms and their related functions than male respondents, who have a high degree of confidence but are lower than those in the first category.

For the differences between gender and the satisfaction of using multimedia tools in the online teaching-learning process, we used an independent t-test. The Levene $F$ test results show that groups are homogeneous, the value of Levene $F=0.77$, at a significance threshold $p>0.05$. There are significant differences between the perception of male students ( $m=2.35, \mathrm{Sd}=1.52)$ and female students $(\mathrm{m}=3.29, \mathrm{Sd}=1.64)$ in terms of the satisfaction of using multimedia tools in the online teaching process. The observed differences are significant, highlighted by the value of the independent $\mathrm{t}$-test, $\mathrm{t}(224)=3.40, \mathrm{p}=0.01<0.05$. Female respondents speak and tend to be more active in using the camera and microphone during meetings on related platforms than 
male respondents, who tend to be more reserved in using the camera, microphone, and tools related to online interactions.

We observed no difference between students from different study years with perceived efficacy of online teaching, satisfaction with online systems, and multimedia instructions in online interactions. For testing, those differences were used One Way Anova.

We used the T-test for independent samples to highlight the differences in perception between students attending a particular university center and the effectiveness of e-learning. The Levene $\mathrm{F}$ test results show that the groups analyzed are homogeneous, the value being Levene $F=2.73$, at a significance threshold $p>0.05$. There are significant differences between the two groups, highlighted by the value of the independent T-test, $t(140)=3.02, p=0.003<0.05$. There are significant differences between the perception of students from Bucharest university centers ( $m=3.74, \mathrm{Sd}=1.59)$ and those from Timisoara university centers $(m=2.86, S d=1.78)$ in terms of the effectiveness of these methods and practices. Respondents from Bucharest university centers tend to perceive online learning more than respondents from Timisoara university centers.

We used the T-test for independent samples to highlight the differences in perception between male and female respondents regarding satisfaction and the teaching process in the online environment. The Levene $F$ test results show that the groups are homogeneous, the value of Levene $F=0.33$, at a significance threshold $p<0.05$. There are significant differences between the average of the two groups, this being highlighted by the value of the independent T-test, $t(224)=4.10, p<0.001$. There are significant differences between the perception of male students ( $m=14.78, S d=7.50)$ and the perception of female students $(m=19.90, S d=7.31)$. Thus, female respondents are more satisfied with the processes and methods that make up the online teaching process.

\section{Conclusions}

In the last period, the teaching process has moved to online. Students had to adapt to the current situation and transition from face-to-face teaching to online teaching with the help of e-learning platforms.

There is a significant difference between female and male respondents regarding the satisfaction of the teaching process in the online environment. The mean of female responses is higher than responses offered by male respondents. These results provided by respondents show us that females are more satisfied with the teaching process in the online environment than male respondents. This phenomenon could 
be explained by female respondents' ability to adapt quickly and use most e-learning platforms and related functions.

There is no significant difference between the student's year and the respondents' utility and perceived efficacy compared to the online teaching process. Thus, this analysis shows us that students perceive equally the processes related to e-learning, regardless of the year from which they come.

It can be observed that regardless of the year of study, the degree of satisfaction does not differ significantly.

The results show no significant differences between male and female individuals regarding perceived self-efficacy and satisfaction with e-learning platforms.

The data showed significant differences between respondents from Bucharest university centers and Timisoara in their desire to use multimedia elements in the online learning process. Thus, respondents from Bucharest university centers tend to use the multimedia elements related to e-Learning platforms with greater openness. One possible explanation for this result could be that university centers in Bucharest would have e-learning/online communication platforms developed before the pandemic, having a technical advantage over respondents in university centers from Timisoara.

Based on the analyses, we have found that there is also a perception that male people are more inclined to use technology. This study reveals that female respondents had a greater openness than male respondents in the case of online education and the use of e-learning platforms.

Based on the analyses carried out by the year of study and the dimensions of satisfaction in the online education process, we noticed that the year of study does not influence respondents' perceptions.

The analyses show that students from university centers in Bucharest are more satisfied with the methods and elements that form the online teaching process than respondents from university centers in Timisoara.

The results should be looked at with reservations, as the data collected are not always homogeneous, and the sample was chosen by voluntary participation method. This research can be seen as a starting point for future research related to the satisfaction of the teaching process through e-learning. 


\section{Bibliography}

1. Arkorful, V., \& Abaidoo, N. (2015). The role of e-learning, advantages and disadvantages of its adoption in higher education. International Journal of Instructional Technology and Distance Learning, 12(1), 29-42.

2. Azlan, A., C., Wong, J. H., Tan, L. K., Huri, M. S., Ung, N. M.,... Ng, K. H. (2020). Teaching and learning of postgraduate medical physics using Internet-based e-learning during the COVID-19 pandemic- A case study from Malaysia. Physica Medica, 11.

3. Chelcea, S. (1975). Chestionarul în investigaţia sociologică. Bucureşti: Editura Ştiinţifică şi enciclopedică.

4. Chou, T. C. R. (2014). A Scale of university students' attitudes toward e-learning on the moodle system. International Journal of Online Pedagogy and Course Design (IJOPCD), 4(3), 49-65.

5. Coppola, M., Senatore, I., \& Masullo, G. (2020). Parents in Pandemic: parents' perceptions of risks and psychological, relational, and pedagogical needs in childhood during the COVID-19 emergency in Italy. Academicus, (22), 103.

6. Downling, C., Godfrey, J. M., \& Gyles, N. (2003). Do hybrid flexible delivery teaching methods improve accounting students learning outcomes? Accounting Education: An International Journal, 374-389.

7. Gandolfi, E. (2018). Taking a Stand through Digital Games. Academicus International Scientific Journal, 9(17), 62-81.

8. Gupta, S. B., \& Gupta, M. (2020). Technology and E-Learning in Higher Education. International Journal of Advanced Science and Technology, 1320-1325.

9. Harasim, L. (2002). Shift happens Online education as a new paradigm in learning. The internet and higher education, 42-44.

10. Hung, M.-L., Chou, C., \& Chao-Hsiu Chen, Z.-Y. O. (2010). Learner readiness for online learning: Scale development and student perceptions. Computers \& Education, 1083.

11. Ilie, S.M. (2007). Implementarea sistemelor E-Learning pentru managementul cursurilor online. eLSE, Bucuresti.

12. Mayes, T., Dineen, F., McKendree, J., \& Lee, J. (2002). Learning from watching others learn. In Networked learning: perspectives and issues (pp. 213-227). Springer, London.

13. Barbour, M. K., \& Reeves, T. C. (2009). The reality of virtual schools: A review of the literature. Computers \& Education, 52(2), 402-416. 
14. Mpofu, B. (2016). University students use of computers and mobile devices for learning and their reading speed on different platforms. Universal Journal of Educational Research, 4(4), 926-932.

15. Murairwa, S. (2015). Voluntary sampling design. International Journal of Advanced Research in Management and Social Sciences, 4(2), 185-200.

16. Obrad, C. (2018). Cercetarea sociologică, De la proiect la raport. Timişoara: Editura de Vest.

17. Palloff, R. M., \& Pratt, K. (1999). Building Learning Communities in Cyberspace: Effective Strategies. San Francisco: Jossey-Bass.

18. Haavind, S. (2005, October). Facilitating deepened online learning. In E-Learn: World Conference on E-Learning in Corporate, Government, Healthcare, and Higher Education (pp. 696-708). Association for the Advancement of Computing in Education (AACE).

19. Rosenberg, M. J., \& Foshay, R. (2002). E-learning: Strategies for delivering knowledge in the digital age.

20. Grawitz, M., \& Pinto, R. (1972). Méthodes des sciences sociales. Paris: Dalloz. 